\title{
Alcohol, Wine and Platelet Function
}

\author{
JEAN-CLAUDE RUF
}

The "Wine, Nutrition \& Health" Unit of the "Office International de la Vigne et du Vin", intergovernmental organization, Paris, France.

\begin{abstract}
Epidemiological studies have demonstrated an inverse correlation between moderate wine and alcohol consumption and morbidity and mortality from coronary heart disease.

The protective effect has been associated with an increase in the plasma level of HDL cholesterol, as it is well recognized that plasma HDL is inversely correlated with CHD. In addition, it has become evident that blood platelets contribute to the rate of development of atherosclerosis and CHD through several mechanisms. In recent studies it has been shown that the level of HDL cholesterol can explain only $50 \%$ of the protective effect of alcoholic beverages; the other $50 \%$ may be partly related to a decrease in platelet activity.

This anti-platelet activity of wine is explained by ethanol but also by the polyphenolic components with which red wines are richly endowed.

Several studies carried out on humans and animals have shown that wine phenolics could exert their effects by reducing prostanoid synthesis from arachidonate. In addition, it has been suggested that wine phenolics could reduce platelet activity mediated by nitric oxide. Moreover, wine phenolics increase vitamin E levels while decreasing the oxidation of platelets submitted to oxidative stress.

However, a rebound phenomenon of hyperaggregability is observed after an acute alcohol consumption which is not observed with wine consumption. This protection afforded by wine has been duplicated in animals with grape phenolics added to alcohol. The rebound phenomenon may explain ischemic strokes or sudden deaths known to occur after episodes of drunkenness.

It appears that wine, and wine phenolics in particular, could have a more significant inhibitory effect on platelet aggregation and could explain, in part, the hypothesis that red wine is more protective against atherosclerosis and coronary heart disease.
\end{abstract}

Key words: Alcohol, cardiovascular disease, platelet function, wine.

Abbreviations: CFR: cyclic flow reduction; DHA: docosahexaenoic acid; EDRF: endothelium derived relaxing factor; 12-HETE: 12-hydroxyeicosatetraenoic acids; HHT: hydroxyheptadecatrienoic acid; LDL: low-density lipoprotein; MDA: malondialdehyde; NO: nitric monoxide; PGI2, PGD2: prostacyclin; PMN: polymorphonuclear leukocytes; TXA2: Thromboxane A2.

\section{INTRODUCTION}

It has been shown in epidemiological studies that moderate consumption of alcoholic beverages has a protective effect against the clinical complications of coronary heart disease (1).

Several reasons have been proposed for this protective effect, including increased plasma levels of high density lipoproteins or prostacyclin that are associated with ingestion of alcohol and direct inhibitory effects on platelet function $(2,3)$.

Blood platelets interact with coagulation factors and the blood vessel wall to maintain the integrity of the vessels and hemostasis. They are also active in the initiation of thrombosis within the development of atherosclerosis.

Platelets are closely related to fatal or non-fatal myocardial infarction. It is well known that patients with diabetes, hypertension, and patients who smoke have hyperactive blood platelets.

Platelet activation is due to the action of a different agonist on the blood platelet. Platelet activation could be mediated by different components that come from plasma (thrombin), vascular wall (collagen) or platelets themselves (ADP, TXA2). 
The release of arachidonic acid from plasma membrane phospholipids by phospholipase A2 leads to the formation of thromboxanes, prostaglandins, and leukotrienes (4). Thromboxane A2 (TXA2), is an unstable product, which plays an important role in propagating aggregation, once this process has been initiated. Thromboxane B2 and hydroxyheptadecatrienoic acid (HHT) are two stable products formed from TXA2.

The other pathway from arachidonate expressed in platelets involves the 12lipoxygenase enzyme, which synthesizes a family of eicosanoids leading to the production of 12-hydroxyeicosatetraenoic acids (12-HETE) that are involved in calcium mobilization and vascular permeability.

Another activation is mediated by thrombin, which activates phospholipase C and induces the release of inositol triphosphate through the hydrolysis of phosphatidyl inositol, which increases calcium mobilization.

Some vascular components could inhibit platelet aggregation, such as prostacyclin (PGI2, PGD2) or endothelium derived relaxing factor (EDRF) identified as nitric monoxide (NO). This inhibition is mediated by the release of AMPc through the activation of adenylate cyclase.

There is some clinical and epidemiological evidence suggesting that moderate alcohol consumption, especially wine, is associated with a reduction in the risk of coronary heart disease (5-7).

A number of studies have demonstrated that moderate consumption of alcohol raises HDL-cholesterol levels. However, it has been suggested that the increase of HDLcholesterol could explain about half of the beneficial effect of moderate alcohol consumption $(1,12)$. A number of other mechanisms have been proposed to explain the other half of the protective effect. These observations suggest a direct effect of ethanol on hemostasis and a possible effect on blood clotting $(13,14)$. Other studies have focused on the non-alcoholic components of alcoholic beverages, particularly in red wine, which may reduce platelet activity and improve the vasorelaxant effects.
EFFECTS OF ALCOHOL ON PLATELET AGGREGATION

Alcohol influences several blood parameters which could explain its protective effects. It is well known that alcohol consumption raises HDLcholesterol concentrations and thereby reduces the development of atherosclerosis. However, many studies have also demonstrated that alcohol affect hemostatic parameters (12-15).

An explanation for the protective action of ethanol pertains to its effect on platelets, which play a critical role in thrombosis and the pathogenesis of atherosclerosis $(16,17)$.

Numerous studies have investigated the effect of alcohol on platelet aggregation. All tend to demonstrate that alcohol added in vitro leads to a significant decrease of platelet aggregation induced by thrombin, collagen, epinephrine and ADP (17-20).

Human studies have shown that physiological concentrations of ethanol inhibit platelet aggregation in humans as well as in animals in response to several agonists, like collagen, thrombin, ADP and platelet activating factor $(21,22)$.

In the Caerphilly Prospective Heart Disease Study (23) it appears that the intake of alcohol was inversely associated with the response of platelets to aggregation induced by collagen and ADP. Since, it has been demonstrated that, like aspirin (24), alcohol inhibits the secondary aggregation; it can be postulated that alcohol inhibits the release of TXA2 induced by different agonists $(25,26)$. The mechanism by which alcohol reduces TXA2 formation acts by inhibiting the activity of platelet phospholipase A2 (17, 20). Phospholipase A2 leads to the hydrolysis of the phospholipid membrane -mainly of phosphatidyl-choline and phosphatidyl-ethanolamine- and, at least, to the release of arachidonic acid. By contrast, it seems that an inhibitory effect of alcohol on thrombin-induced aggregation is not observed in unselected populations with moderate alcohol consumption. This lack of inhibitory effect of alcohol on thrombin-induced aggregation could be explained if alcohol 
caused an immediate and general inhibitory effect on platelet function, but the inhibitory effect on thrombin-induced aggregation was transitory. This suggestion comes from different animal studies $(15,21)$.

In some studies, it has been found that ethanol also inhibits production of inositol tri-phosphate by platelets stimulated with low concentrations of thrombin that do not cause formation of TXA2 (27). This finding indicates that ethanol has an inhibitory effect on the activation and/or the activity of phospholipase $\mathrm{C}$, which is considered the second type of platelet activation.

In acute studies, different results suggest that platelet reactivity is significantly but transiently increased in alcoholics 1-2 weeks after ethanol withdrawal and in healthy volunteers after acute ethanol ingestion (1.5 g alcohol/kg body weight) (28).

THE EFFECTS OF WINE AND POLYPHENOLS ON PLATELET AGGREGATION

\section{Human and experimental studies}

Many studies have investigated the effect of wine or wine phenolics on platelet activation and aggregation (29).

Several results have demonstrated a significant inhibitory effect of red wine in ADP and thrombin-induced platelet aggregation (30-33).

Seigneur et al. demonstrated a marker difference with red wine which reduced rather than enhanced ADP-induced aggregation. This would seem to indicate a significant role of polyphenolic compounds of red wine.

In human experiments Pace-Asciak et al. (33) have demonstrated a significant antiaggregatory effect with red and white wine. Inhibition of aggregation is evidenced by an increase in the concentration of agonist required to aggregate $50 \%$ of the cells under standard conditions (IC50). A significant increase occurred in the IC50 for thrombin with both white wine $(31 \%)$ and red wine (49\%). By contrast, white wine consumption reduced plasma TXB2 concentration by $52.5 \%$ and red wine by $59.4 \%$. Concerning ADP during white wine as well as red wine consumption, the IC50 for ADP increased by $17 \%$.

In addition, there have been numerous reports that wines and particularly red wine and also flavonoids and resveratrol can have beneficial effects on platelet function in animals.

The Folts coronary thrombosis model is an on-line in vivo bioassay for platelet activity producing cyclic flow reduction (CFR) in coronary blood flow. The CFRs were eliminated by intravenous or intragastric administration of red wine $(4 \mathrm{ml} / \mathrm{kg})$ or grape juice. Similar administration of white wine, however, was without effect (34).

On the other hand, some results on the effects of flavonoids on platelet aggregation have demonstrated antiaggregatory effects (35-38). It seems that epicatechin was more effective than catechin to inhibit the arachidonic acid induced-platelet aggregation in dose-dependent manner. Other studies have compared different wine phenolics and some standard anti-oxidants.

Some results show that among the wine phenolics tested, catechin and epicatechin had little effect, but quercetin and transresveratrol inhibited both thrombin and ADP-induced platelet aggregation (35). Other studies indicated that after consumption of alcohol alone or alcohol supplemented with grape polyphenols, platelets showed a significant decrease in aggregability in response to thrombin, which was greater for alcohol supplemented with grape polyphenols (39).

Other investigations had also shown that resveratrol was the only wine polyphenol that inhibited the production of plasma TxB2 from arachidonate by human platelets and this was also accompanied by reduced synthesis of HHT, a stable intermediate of the cyclo-oxygenase pathway (40).

De-alcoholized red wine low in resveratrol, thrombin and ADP induce platelet aggregation but to a lesser extent. Tzeng et al. (41) showed that ADP, epinephrine or arachidonic acid-induced platelet aggregation was inhibited by different wine phenolics like myricetin and 
quercetin. These results have been confirmed by other investigations (42-44).

Other studies have investigated the effect of resveratrol, a natural phytoalexin found in red wine, on platelet aggregation $(35,45)$. Using ADP and thrombin as agonists, a dose-dependent inhibition of human platelet aggregation by both trans-resveratrol and quercetin has been demonstrated. Bertelli et al. $(46,47)$ demonstrated a dose-dependent inhibition of collagen-induced platelet aggregation by resveratrol. Moreover, they also found a strong inhibitory effect of the 1000 -fold diluted red wine (final resveratrol concentration: $1.2 \mu \mathrm{g} / \mathrm{l})(-41.9 \%)$ indicating a platelet activity of different compounds, such as alcohol and flavonoids. However, in the same diluted wine, the addition of synthetic resveratrol at a very low dose $(+1.2 \mu \mathrm{g} / \mathrm{l})$ increased significantly the platelet inhibitory effect (-78.5) showing an interaction between resveratrol and red wine components.

\section{Grape juice studies}

In Folts coronary thrombosis model, grape juice was used (34). The animals received $6-8 \mathrm{ml} / \mathrm{kg}$ of grape juice via intragastric administration and showed platelet inhibition evidenced by a decrease in the slopes of the CFR, but they were not completely eliminated.

The CFR was completely abolished with the administration of $10 \mathrm{ml} / \mathrm{kg}$ of grape juice after an average of 95 minutes, which coincided with a significant decrease in collagen-induced whole-blood platelet aggregation. Similar experiments conducted with orange juice or grapefruit juice had no effects (48).

The amount of intragastric grape juice necessary to abolish the CFR was 2.5-fold greater than the amount of intragastric red wine required. Red wine and grape juice used for this study contained essentially quercetin and rutin, whereas the level of resveratrol was undetectable. However, Pace-Asciak (33) showed that when thrombin was added to it, the commercial grape juice induced a highly significant reduction of IC50. Our experiments also indicated that only the wine with alcohol was associated with a decrease in platelet aggregation compared to water. In contrast, the wine without alcohol increased the response of platelets to aggregation (37).

\section{Platelet rebound effect}

Another antithrombotic effect of wine and of its phenolic compounds is its capacity to prevent the potentially damaging rebound overshoot of platelet aggregation after withdrawal of alcohol, which has been observed in different studies and that result in stroke or sudden death $(37,49)$. In fact, when the animals drank diluted alcohol (6\%) until venipuncture, platelet aggregation to thrombin was inhibited by more than $60 \%$. In animals drinking alcohol or wine, platelet aggregation was inhibited to the same extent as the group of animals receiving the different alcoholic beverages with the same amount of alcohol (6\%).

However, when the same fasted animals were deprived of their alcoholic beverage for 18 hours, a marked rebound effect in platelet aggregation was observed with alcohol. In the same condition this rebound effect was not observed in animals given red wine. White wine had a medium effect.

On the other hand, if some polyphenols are added separately to alcohol up to the level contained in red wine, the effects on platelet aggregation are similar to the inhibitory effect of red wine on the rebound effect observed with alcohol alone. The protective effect of red wine from rebound effects appears to be essentially associated with wine phenolics. This protection was related to an inhibition of the increase in lipid peroxidation observed with alcohol drinking. By contrast, the animals drinking red wine exhibited a reduction of levels of lipid peroxides and conjugated dienes and vitamin E. Also, only wine phenolics added to alcohol were able to protect against lipid peroxidation, similarly to red wine (37).

MECHANISMS INVOLVED IN THE

ANTIAGGREGATORY EFFECT OF WINE PHENOLICS

The anti-aggregatory effect could be mediated through the ability of wine 
phenolics, including catechin, epicatechin, quercetin and resveratrol to inhibit the eicosanoid pathway. Since it has been demonstrated that resveratrol impairs the formation of TXA2 but not quercetin, it has been postulated that quercetin blocks thrombin-induced platelet aggregation by directly inhibiting phospholipase $\mathrm{C}$ activity.

Resveratrol could inhibit cyclooxygenase and lipoxygenase activities (50) and reduce TXA2 production (35). The cyclooxygenase pathway is important in the biosynthesis of TXA2, whereas the lipoxygenase pathway is responsible for the production of hydroxyacids and leukotrienes. TxA2 mobilizes $\mathrm{Ca} 2+$ from intracellular stores; this intracellular elevation of $\mathrm{Ca} 2+$ is likely the final mediator of platelet aggregation and ADP release. It was also demonstrated that even at low concentrations $\left(10^{-6}-10^{-3} \mathrm{~mol} / \mathrm{l}\right)$ resveratrol inhibited the formation of lipoxygenase product and TXB2 by rat peritoneal polymorphonuclear leukocytes, and suppressed ADP-induced platelet aggregation (51).

Although stimulation of platelet adenylate cyclase activity is another possible site of action (35), it seems, however, that quercetin has no effect on intracellular phospholipase A2 from human platelets (52). Polette et al. have shown that the most striking effect of flavonoids on unstimulated platelets was observed on the basal TXB2, with a dosedependent effect. Epicatechin was more effective than catechin to depress TXB2 formation (38).

It can be concluded that wine phenolics and flavonoids are inhibitory at multiple points in the eicosanoid pathway. They potentiate antiaggregatory PGI2 activity, inhibit thromboxane synthesis by inhibiting both lipoxygenase and cyclooxygenase activity, and also block platelet thromboxane receptors $(41,43,44,53)$.

Recent studies show that platelet membrane microviscosity decreased significantly after red wine compared to the control. Moreover platelet membrane fatty acids analysis revealed that the total saturated fatty acids mainly (18:0) showed a tendency to decrease after red wine consumption. Total unsaturated fatty acids (poly and mono unsaturated) showed a tendency to increase after red wine consumption. These results may have synergistic effect in decreasing platelet aggregation (54).

Other mechanisms have been evoked to explain the antiaggregatory effect of polyphenol. Since, some studies have provided direct evidence that wine phenolics induce an endothelial-dependent relaxation via a direct enhancement of endothelial NO synthesis (55-58). It could be suggested that this mechanism could be involved in the antiaggregatory effect of wine phenolics. It has been shown that NO has platelet antiaggregatory properties stimulating guanylate cyclase that induces an increase of intraplatelet GMPc, a component responsible for the platelet inhibition (59).

The anti-oxidant properties of wine phenolics are also involved in the antiaggregatory effect. Some flavonoids such as catechin or epicatechin are able to restore the vitamin $\mathrm{E}$ level or to decrease the malondialdehyde (MDA) formation in platelets co-incubated with docosahexaenoic acid (DHA) (34). Flavonoids have been shown to inhibit the non-enzymatic peroxidation of polyunsaturated fatty acids required for the activation of cyclo- and lipoxygenase (60).

Recent studies provided information concerning the effect of wine polyphenols on the interaction between polymorphonuclear leukocytes (PMN) and platelets, mechanism that is relevant to the progression of vascular damage. PMN adhesion to stimulated platelets can be quantified by cytofluorimetry. Wine polyphenols inhibit PMN adhesion to stimulated platelets in a dose dependent manner. This inhibition is due to the reduction by the wine polyphenols of the expression of the adhesion molecule as $\beta 2$ integrin (MAC-1) $(61,62)$.

\section{CONCLUSION}

Red wines contain a large number of naturally occurring compounds. These include tannins, anthocyanins, phenolic flavonoids compound which have some 
potential health benefits. Some of them are both good platelet inhibitors and good antioxidants. These characteristics could reduce either the development of occlusive platelet mediated thrombi forming in narrowed arteries or the development of atherosclerosis by preventing the oxidation of low-density lipoprotein (LDL). It seems that wine and wine phenolics could act in a protective way on the two mechanisms involved in the development of coronary heart diseases.

\section{REFERENCES}

1. DE WOOD MA, SPORES J, NOTSKE R, MOUSER LT, BURROUGHS R, GOLDEN MS, LANG HT. (1980) Prevalence of total coronary occlusion during the early hours of transmural myocardial infarction. $\mathrm{N}$ Engl J Med 303: 897-902

2. HENNEKENS CH, WILLET W, ROSNER B. COLE DS, MAYRENT SL (1979) Effects of beer wine and liquor in coronary deaths. JAMA, 242: 1973-1974

3. LANDOLFI R, STEINER M (1984) Ethanol raises prostacyclin in vivo and in vitro. Blood, 64: 679-684

4. SMITH WL (1989) The eicosanoids and their biochemical mechanisms of action. Biochem J 259: 315-324

5. RENAUD S, CRIQUI MH, FARCHI G, VEENSTRA J (1993) Alcohol drinking and coronary heart disease. In VERSHUREN PM ed. Health issues related to alcohol consumption. Washington: ILSI Press, p 81

6. GRONBAEK M, DEIS A, SORENSEN TA, BECKER U, SCHNOHR P, JENSEN G (1995) Mortality associated with moderate intakes of wine, beer or spirits. BMJ, 310:1165-1169

7. KLATSKY AL, ARMSTRONG MA (1992) Alcoholic beverage choice and risk of coronary artery disease mortality: Do red wine drinkers fare best? Am J Cardiol 71:467-469

8. LANGER RD, CRIQUI MH, REED DM (1992) Lipoproteins and blood pressure as biologic pathways for the effect of moderate alcohol consumption on coronary heart disease. Circulation, 85, 910-915

9. SUH I, SHATEN BJ, CUTLER JA, et al. (1992) Alcohol use and mortality from coronary heart disease: The role of high-density lipoprotein cholesterol. Ann Intern Med 116: 881-887

10. PEARSON TA (1996) Alcohol and heart disease. Circulation 94: 3023-3025

11. GOLDBERG DM, HAHN SE, PARKES JG (1995) Beyond alcohol: Beverage consumption and cardiovascular mortality. Clin Chim Acta 237: 155-187

12. RIDKER PM, VAUGHAN DE, STAMPFER MJ, GLYNN RJ, HENNEKENS CH (1994) Association of moderate alcohol consumption and plasma concentration of endogenous tissue-type plasminogen activator. JAMA 272: 929-933

13. HENDRIKS HF, VEENSTRA J, VELTHUIS-TE WIERIK EJ, SCHAAFSMA G, KLUFT C (1994) Effect of moderate dose of alcohol with evening meal on fibrinolytic factors. BMJ 308: 1003-1006

14. RUBIN R (1990) Effects of ethanol on platelets Lab Invest $63,729-732$
15. HAUT MJ, COWAN DH (1974) The effect of ethanol on hemostatic properties of human blood platelets. Am J Med 56, 22-33

16. RAND ML, GROVES HM, PACKHAM MA, MUSTARD JF, KINLOUGH-RATHBONE RL (1990) Acute administration of ethanol to rabbits inhibits thrombus formation induced by indwelling aortic catethers. Lab Invest 63: 742-745

17. RUBIN R (1988) Ethanol interferes with collageninduced platelet activation by inhibition of arachidonic acid mobilization. Arch Biochem Biophys 270: 99-113

18. BENISTANT C, RUBIN R (1990) Ethanol inhibits thrombin-induced secretion by human platelets at a site distinct from phospholipase $\mathrm{C}$ or protein kinase $\mathrm{C}$. Biochem J 269: 489-497

19. MIKHAILIDIS DP, BARRADAS MA, JEREMY JY (1990) The effect of ethanol on platelet function and vascular prostanoids. Alcohol 7: 171-80

20. RAND ML, PACKAM MA, KINLOUGH-RATHBONE RL, FRASER MUSTARD J (1988) Effects of ethanol on pathways of platelet aggregation in vitro. Thromb Haemost 59: 383-387

21. RENAUD S, McGREGOR L, MARTIN JL (1984) Influence of alcohol on platelet functions in relation to atherosclerosis. In: Pozza G, et al., eds. Diet, diabetes and atherosclerosis. New York: Raven Press, p 177

22. MEADE TW, VICKERS MV, THOMPSON SG, SEGHATCHIAN MJ (1985) Epidemiological characteristics of platelet aggregability. BMJ 290: 428432

23. RENAUD S, BESWICK AD, FEHILY AM, SHARP DS, ELWOOD PC (1992) Alcohol and platelet aggregation: The Caerphilly Prospective Heart Disease Study. Am J Clin Nutr 55: 1012-1017

24. ZUCKER MB, PETERSON J (1968) Inhibition of adenosine diphosphate-induced secondary aggregation and other platelet functions by acetylsalicylic acid ingestion. Proc Soc Exp Biol Med 127: 547-551

25. TOIVANEN J, YLIKORKALA O, VIINIKKA L (1983) Ethanol inhibits platelet thromboxane A2 production but has no effect on lung prostacyclin synthesis in human. Thromb Res 33:1-8

26. MIKHAILIDIS DP, JEREMY JY, BARRADAS MA, GREEN N, DANDONA P (1983) Effect of ethanol on vascular prostacyclin (prostaglandin I2) synthesis, platelet aggregation, and platelet thromboxane release. BMJ 287: 1495-1498

27. RAND ML, VICKERS JD, KINLOUGH-RATHBONE RL, PACKHAM MA, MUSTARD JF (1988) Thrombin induced inositol triphosphate production by rabbit platelet is inhibited by ethanol. Biochem. J. 251: 279284

28. HILLBOM M, KANGASAHO M, HJELM-JAGER M (1984) Platelet aggregation and thromboxane B2 formation after ethanol abuse: Is there a relationship to stroke? Acta Neurol. Scand. 70: 432-437

29. RENAUD S, DE LORGERIL M (1992) Wine, alcohol, platelets, and the French Paradox for coronary heart disease. Lancet 339: 1523-1526

30. SEIGNEUR M, BONNET J, DORIAN B BENCHIMOL D, DROUILLET F, GOUVERNEUR G, LARRUE J, CROCKETT R, BOISSEAU MR, RIBERAU-GAYON P \& BRICAUD H. (1990) Effect of the consumption of alcohol, white wine, and red wine on platelet function and serum lipids. J. Appl. Cardiol. 5: 215-222

31. FOLTS JD, BEGOLLI B, SHANMUGANAYAGAM D (1996) Red wine, atherosclerosis, and coronary thrombosis Wine in context Eds Waterhouse AL, Rantz JM. American Society for Enology and Viticulture.p 13 
32. STRUCK M, WATKINS T, TOMEO A, HALLEY J, BIERENBAUM M. (1994) Effect of red and white wine on serum lipids, platelet aggregation, oxidation products and antioxidants: a preliminary report. Nutr Res 1994;14:1811-1819.

33. PACE-ASCIAK CR, ROUNOVA O, HAHN SE, DIAMANDIS EP, GOLDBERG DM. (1996) Wines and grape juices as modulators of platelet aggregation in healthy human subjects. Clin Chim Acta 246: 163-182

34. DEMROW HS, SLANE PR, FOLTS JD (1995) Administration of wine and grape juice inhibits in vivo platelet activity and thrombosis in stenosed canine coronary arteries. Circulation 91: 1182-1188

35. PACE-ASCIAK CR, HAHN S, DIAMANDIS EP, SOLEAS G, GOLDBERG DM (1995) The red wine phenolics trans resveratrol and quercetin block human platelet aggregation and eicosanoid synthesis: Implications for protection against coronary heart disease. Clin Chim Acta 235: 207-219

36. FORMICA JV, REGELSON W (1995) Review of the biology of quercetin and related bioflavonoids. Food Chem Toxicol 33: 1061-1080

37. RUF JC, BERGER JL, RENAUD S (1995) Platelet rebound effect of alcohol withdrawal and wine drinking in rats. Relation to tannins and lipid peroxidation. Arterioscler Thromb Vasc Biol 1: 140144

38. POLETTE A, LEMAitre D, LAGARDE M, VERICEL E (1996) N-3 Fatty acid induced lipid peroxidation in human platelets is prevented by catechins. Thromb Haemost 75: 945-949

39. XIA J, ALLENBRAND B, SUN GY (1998) Dietary supplementation of grape polyphenols and chronic ethanol administration on LDL oxidation and Platelet function in rats. Life Sciences, 63:383-390

40. PACE-ASCIAK CR, HAHN S, DIAMANDIS EP, SOLEAS G, GOLDBERG DM (1995) The red wine phenolics, trans resveratrol and quercetin block human platelet aggregation and eicosanoid synthesis: implications for protection against coronary heart diseases. Clin Chim Acta 236:207-219

41. TZENG S, KO W, KO FN, TENG CM (1991) Inhibition of platelet aggregation by some flavonoids. Thromb Res 64: 91-100

42. LANZA F, BERETZ A, STIERLE A, CORRE G, CAZENAVE JP (1987) Cyclic nucleotide phosphodiesterase inhibitors prevent aggregation of human platelets by raising cyclic AMP and reducing cytoplasmic free calcium mobilization. Thromb Res 45: 477-484

43. BERETZ A, STIERLE A, ANTON R, CAZENAVE JP (1982) Role of cyclic AMP in the inhibition of human platelet aggregation by quercetin, a flavonoid that potentiates the effect of prostacyclin. Biochem Pharmacol 31: 3597-3600

44. GRYGLEWSKI RJ, KORBUT R, ROBAK J, SWIES J (1987) On the mechanism of anti-thrombotic action of flavonoids. Biochem Pharmacol 36: 317-322

45. SOLEAS GJ, DIAMANDIS EP, GOLDBERG DM (1997) Resveratrol: A molecule whose time has come? and gone? Clin Biochem 30: 91-113

46. BERTELLI AA, GIOVANNINI L, GIANNESSI D, MIGLIORI M, BERNINI W, FREGONI M, BERTELLI A (1995) Antiplatelet activity of synthetic and natural resveratrol in red wine. Int $\mathrm{J}$ Tissue React 17: $1-3$

47. BERTELLI AA, GIOVANNINI L, BERNINI W, MIGLIORI M, FREGONI M, BAVARESCO L,
BERTELLI A (1996) Antiplatelet activity of cisresveratrol. Drug Exptl Clin Res 22: 61-63

48. KEEVIL JG, OSMAN HE, REED JD, FOLTS JD (2000) Grape juice, but not orange juice or grapefruit juice, inhibits human platelet aggregation. J Nutr 130: 53-56

49. RENAUD S, RUF JC (1996) Effects of alcohol on platelet functions. Clin Chim Acta 246: 77-89

50. WU JM, WANG ZR, HSIEH TC, BRUDER JL, ZOU JG, HUANG YZ (2001) Mechanism of cardioprotection by resveratrol a phenolic antioxidant present in red wine. Int J Molec Med 8: 3-17

51. KIMURA Y, OKUDA H, ARICHI S (1985) Effects of stilbenes on arachidonate metabolism in leukocytes. Biochim Biophys Acta 834:275-278

52. FAWZY AA, VISHWANATH BS, FRANSON RC (1988) Inhibition of human non-pancreatic phospholipases A2 by retinoids and flavonoids. Mechanism of action. Agents Actions 25: 394-400

53. YOSHIMOTO T, FURUKAWA M, YAMAMOTO S, HORIE T, WATANABE-KOHNO S. (1983) Flavonoids: potent inhibitors of arachidonate 5lipoxygenase. Biochem Biophys Res Común.116: 612618

54. MANSVELT EPG, VAN VELDEN DP, FOURIE E, ROSSOUW M, VAN RENSBURG SJ, SMUTS CM. (2001) The in vivo antithrombotic effect of moderate and regular wine consumption on human blood platelets and haemostatic factors. In Proceedings of XXVI World Congress of Vine and Wine OIV, 222

55. ANDRIAMBELOSON E, KLESCHYOV AL, MULLER B, BERETZ A, STOCLET JC, ANDRIANTSITOHAINA R (1997) Nitric oxide production and endothelium-dependent vasorelaxation induced by wine polyphenols in rat aorta $\mathrm{Br} \mathrm{J}$ Pharmacol 120: 1053-1058

56. FITZPATRICK DF, HIRSCHFIELD SL, COFFEY RG (1993) Endothelium-dependent vasorelaxing activity of wine and other grape products. Am J Physiol 265: H774-H778

57. FREEDMAN JE, PARKER C 3RD, LI L, PERLMAN JA, FREI B, IVANOV V, DEAK LR, IAFRATI MD, FOLTS JD (2001) Select flavonoids and whole juice from purple grapes inhibit platelet function and enhance nitric oxide release. Circulation 103: 27922798

58. CUEVAS AM, GERMAIN AM (2004) Diet and Endothelial Function. Biol Res 37: 225-230

59. YAO SK, OBER JC, KRISHNASWAMI A, FERGUSON JJ, ANDERSON HV, GOLINO P, BUJA LM, WILLERSON JT (1992) Endogenous nitric oxide protects against platelet aggregation and cyclic flow variations in stenosed and endothelium injured arteries. Circulation 86: 1302-1309

60. SWAIN T (1986) The evolution of flavonoids. In Progress in clinical and biological research. Vol 213 Eds Liss AR New York by Cody V. Middleton Jr and Harborne JB. p 1

61. ROTONDO S, RAJTAR G, MANARINI S, CELARDO A, ROTILLO D, DE GAETANO G, EVANGELISTA V, CERLETTI C (1998) Effect of trans resveratrol, a natural polyphenolic compound, on human polymorphonuclear leukocyte function. $\mathrm{Br} \mathrm{J}$ Pharmacology 123: 1691-1699

62. ROTONDO S, DE GAETANO G (2000) Wine and cardiovascular disease: a European project. In Proceedings of XXV World Congress of Vine and Wine OIV, 23-32 